\title{
Design of an advanced prototype robot for white asparagus harvesting
}

\author{
Anna P. Chatzimichali, Ioannis P. Georgilas and Vassilios D. Tourassis
}

\begin{abstract}
Agricultural workplaces are a prototypical example of unstructured and variant environments, offering a novel challenge to robotic research and automation. In this paper, a robot prototype is presented for white asparagus harvesting. White asparagus is a rather delicate vegetable with unique cultivation characteristics, which is exceptionally tiring and laborious to collect and requires specialized workers for harvesting. In this paper, we propose an integrated robotic system able to move in the field, identify white asparagus stems and collect them without damaging them. We highlight the design decisions for every module of the harvester and outline the overall architecture of the system.
\end{abstract}

\section{INTRODUCTION}

Asparagus harvesting is a highly repetitive and labor intensive manual task demanding seasonal and regional workers. Additionally, due to the fact that hand harvesting is a very difficult yet relatively low-paid seasonal occupation, the number of workers available for asparagus harvesting is continuously decreasing. Considering also that about half of the customer price of asparagus (currently fetching 2,3€ per kilo in European markets) is attributed to labour costs (estimated at $1 €$ per kilo), the need for automated solutions is becoming vital for the future of asparagus harvest.

Automating asparagus harvesting has a very long history and since 1907 inventors, engineers and entrepreneurs have been attempting to mechanize it [1], [2], [3]. Most of these efforts, whether selective or non-selective, have been focused on green asparagus since it grows above the surface of soil and thus it is easier to collect, as opposed to white asparagus that grows below the surface of the ground.

The best known research program on selective, green asparagus harvesting is conducted at the Centre for Advanced Manufacturing and Industrial Automation (CAMIA) in the University of Wollongong [4]. The CAMIA harvester employs a fiber-optic photoelectric sensor system to detect optimum harvest length. Using microprocessor

Manuscript received January 31, 2009.

A.P. Chatzimichali is a Ph.D. candidate in the Department of Production Engineering and Management, Democritus University of Thrace, Greece (corresponding author, phone +306946912710 , email: axatzimi@pme.duth.gr)

I.P. Georgilas is a Ph.D candidate in the Department of Production Engineering and Management, Democritus University of Thrace, Greece (corresponding author, phone +306977432602, fax: +302541079343, email: igeorila@pme.duth.gr)

V.D. Tourassis is Professor and Head of the Department of Production Engineering and Management, Democritus University of Thrace, Greece (vtourasi@pme.duth.gr) technology, this machine was able to select and remove spears of pre-determined height, leaving anything shorter to future harvesting.

Recently, the German company ASM Dimantec, presented a prototype of a semi-automated harvesting machine for white asparagus, equipped with a joystick, laser beams and swing gripper, which is expected to go on production in late 2009 .

In this paper we argue that the harvest of such a delicate crop can be effectively done using fully automated robotics and vision in the lieu of manual labor. To this end, in Section II the horticultural characteristics of white asparagus as well as the basics of manual harvesting are briefly discussed. In Section III, the architecture of the proposed robotic mechanism is described, via a full discussion of its mechatronic aspects. Finally, in Section IV we discuss avenues for further research on the subject.

\section{ASPARAGUS CULTIVATION}

White asparagus is cultivated in parallel trapezoid mounds (raised beds), up to $35 \mathrm{~cm}$ tall and they are harvested just after the tip of the spears emerges from the mound. The spear needs to be cut about $20 \mathrm{~cm}$ to $25 \mathrm{~cm}$ under the soil, in a short period of time after the appearance of the tip, otherwise a violet coloration appears, resulting in decreased product quality and of subsequently selling price.

Each mount is covered with plastic film to decrease water loss, to raise the relative humidity and to protect the crop from the cold. Workers are lifting the plastic film to cut each asparagus, using specially curved knives designed to cut below the level of soil, and then replace the film. After their harvest asparagus should be cooled immediately. The length of time between harvest and hydro-cooling should be less than two hours, as during this period the spear loses water. Since the spears tend to grow fast, it is necessary to harvest each field twice per day.

To cope with the outlined requirements and the special conditions related to the environment, in the following section we define the specifications of the harvesting mechanism.

\section{DESIGN OF THE ROBOTIC SYSTEM}

To establish the principles of the concept of a fullyautomated asparagus harvester and to tackle the complex interdisciplinary issues related to the design of the robot mechanism, we must focus on defining system requirements. According to the conditions described above, the robotic system must meet three main requirements. 


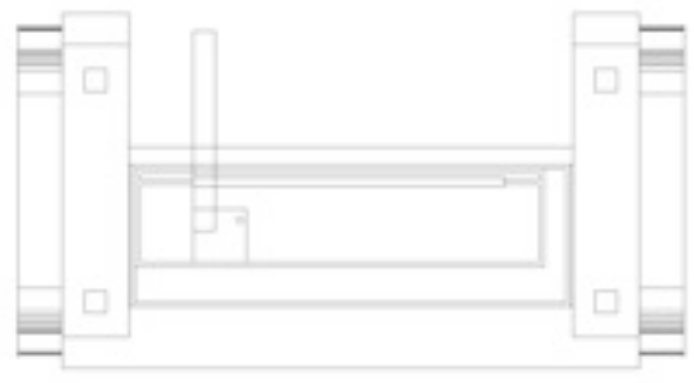

Figure 1: Top view

1. Smooth terrain mobility

2. Effective asparagus identification

3. Accurate cutting and collecting

On a second level, and given the special conditions described in the previous section, the following design specifications should be satisfied.

- $\quad$ Robust body suitable for moving in soft or hard soil.

- Adjustable height to adapt on the mount.

- Motion synchronization and control.

- Identification and collection of asparagus.

- Mechanism for lifting and replacing plastic film.

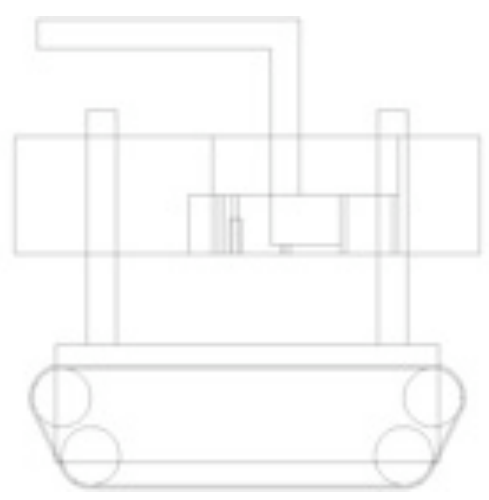

Figure 2: Side view

To develop and implement such a novel harvesting system, mature technologies should be coupled with innovative approaches regarding robotic platform systems, pattern recognition, vision algorithms and high technology sensor systems. The structure of the proposed mechatronic system is described below, regarding its mechanical design, its electronic systems and finally the software and control needed for its operation.

\section{A. Mechanical Design}

The robotic platform is composed of three main sections:

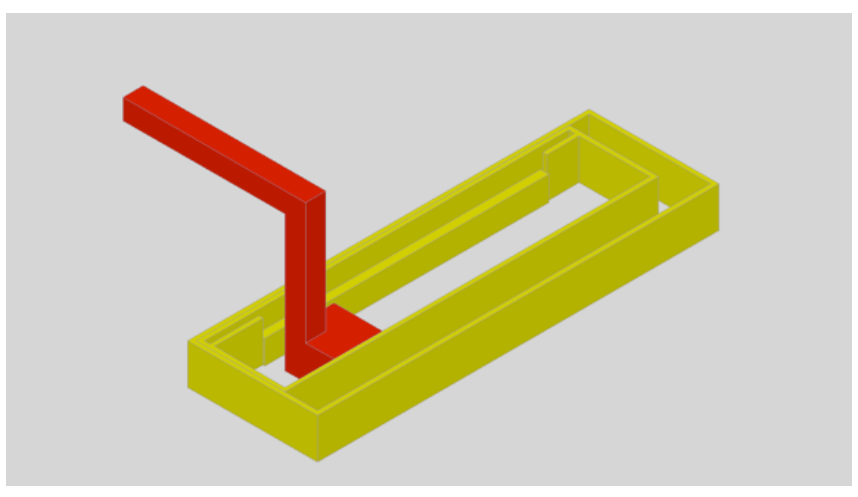

Figure 3: Collection head (red) and Cutting frame (yellow)

the body of the robot, the caterpillar moving system and the collection section.

The prototype is expected to use caterpillars for a smoother movement in the field. The mechanism will move above the mount, utilizing retractable (varying height) legs and the body of the robot will pitch $10^{\circ}$ to 150 to maintain a parallel position with the ground. The caterpillars will move along side of the mount and the legs will adjust the distance between the cutting mechanism and the soil.

In Figures 1 and 2, two views of the robot can be seen. Figure 1 is the top view, where we can clearly distinguish the front section of the body, along with the collection section and finally the storage area. The first section of the body includes the electronic systems, the power supply, the pneumatic pump, camera A and the rest of the necessary apparatus. The second section is the collection mechanism, including the cutting frame and the collection head. The collection head consists of a cutting apparatus, a collection

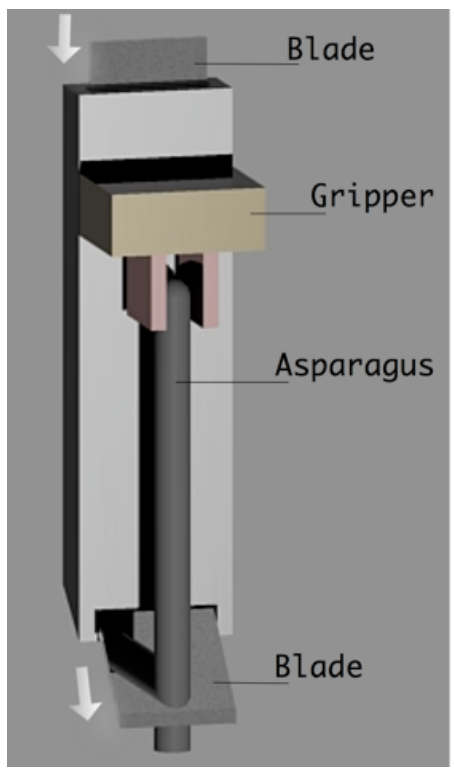

Figure 4: Cutting mechanism and gripper

gripper, camera B and an air spraying pistol. Finally, the third section (the empty space in the figure) will house a 


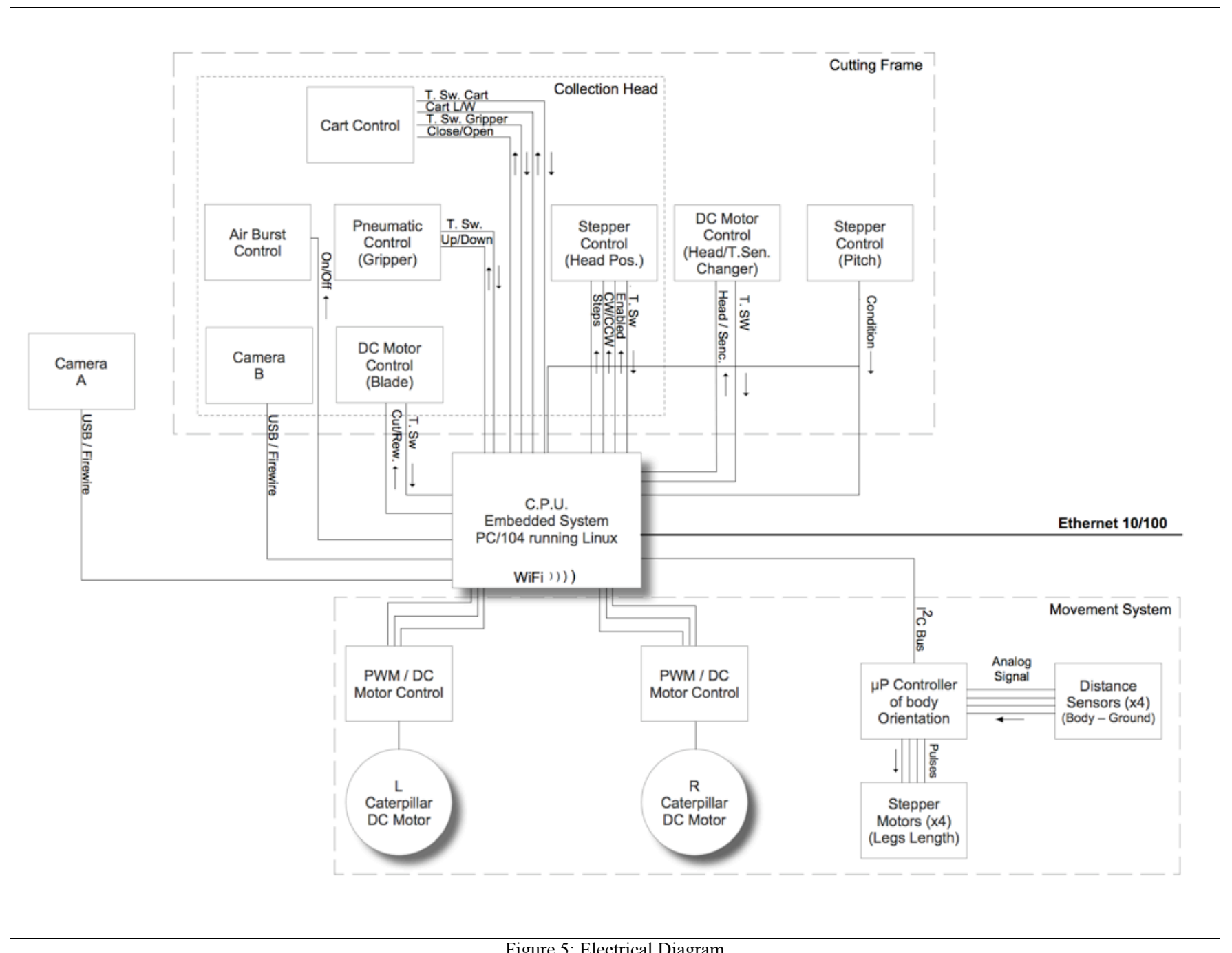

Figure 5: Electrical Diagram

sun-protected water tub as a storage container. Above the main body of the robot an existing commercial system for uncovering and covering the mount from the protecting plastic film will be installed.

In Figure 2, the side view of the caterpillar and the legs are illustrated. Caterpillars are crucial for the smooth functionality of the robot as the terrain is rough and the use of an appropriate movement system is necessary. The connecting legs between the caterpillars and the body are of varying length, utilizing four stepper motors, one located on each leg that accordingly to the distance from the soil will lower or raise the body. Through a self-leveling mechanism the robot will maintain a horizontal position above the soil in order to simplify the collection process.

The collection head will utilize a pneumatic gripper and cutter used for asparagus, customized with the addition of suitable sensors and control (fig. 4). A pneumatic gripper for asparagus collection, with fine force feedback and a fuzzy controller, is described by Mattiazzo et al. in [5]. The gripper, the cutter, camera B and the air pistol will move along the cutting frame. The air pistol will clear dust around the tip of the asparagus making precise positioning of the camera even easier.

The movement of the cutting frame will be controlled by electronic circuits located, in the front section. A stepper driven linear system, will accurately position the cutting frame above the asparagus tip. It will also provide a slight pitching angle as an auxiliary aid to the pitch ability of the body.

\section{B. Electronic Design}

Control over the electrical subsystem will be handled by a PC/104 Embedded Linux board running customized C program. A microprocessor will be used only for the orientation of the body due to the need for a closed loop PID controller to maintain continuously the horizontal position. This configuration allows for easier implementation and simplified system monitoring and control. The electrical diagram can be seen in Figure 4 and is divided into the three segments.

In the center of the system lies the central control component, the Linux embedded system and the signals for the operation of each submodule are analytically presented. Signal control is executed directly by the main board with the only exception the use of $\mathrm{I} 2 \mathrm{C}$ bus for the communication of the board with microprocessor controlling the body orientation. Finally the two cameras, are connected with the C.P.U via USB/firewire. 
Interaction with the operator for operation monitoring, inspection and service can be performed using two different methods, either wireless IEEE 802.11, with the operator standing close to the service station, or wired Ethernet mainly for maintenance actions.

TABLE 1: Electronic Operations

\begin{tabular}{|l|l|}
\hline \multicolumn{1}{|c|}{ Name } & \multicolumn{1}{|c|}{ Operation } \\
\hline Cart Control & $\begin{array}{l}\text { The control circuitry for the operation of the } \\
\text { mechanism collecting the asparagus off the gripper } \\
\text { and moving in to storage area. }\end{array}$ \\
\hline Air Burst Control & $\begin{array}{l}\text { A pneumatic valve and the necessary circuitry for an } \\
\text { auxiliary burst of air to clear dust from around the } \\
\text { tip of asparagus, allowing more accurate recognition } \\
\text { and gripper positioning. }\end{array}$ \\
\hline $\begin{array}{l}\text { Pneumatic Control } \\
\text { (Gripper) }\end{array}$ & $\begin{array}{l}\text { The valve and controlling circuits for the operation } \\
\text { of the gripper collecting the asparagus. }\end{array}$ \\
\hline $\begin{array}{l}\text { DC Motor Control } \\
\text { (Blade) }\end{array}$ & $\begin{array}{l}\text { The controller of the DC motor actuating the cutting } \\
\text { blade. }\end{array}$ \\
\hline $\begin{array}{l}\text { Stepper Control } \\
\text { (Head Position) }\end{array}$ & $\begin{array}{l}\text { The stepper motor controller to achieve specific } \\
\text { positioning of the cutting frame. }\end{array}$ \\
\hline $\begin{array}{l}\text { DC Motor Control } \\
\text { (Head/Camera } \\
\text { Changer) }\end{array}$ & $\begin{array}{l}\text { The motor controller for the switch between camera } \\
\text { and gripper on the cutting frame. }\end{array}$ \\
\hline $\begin{array}{l}\text { Stepper Control } \\
\text { (Pitch) }\end{array}$ & $\begin{array}{l}\text { The stepper controller of the fine-tuning of pitch in } \\
\text { the front section. }\end{array}$ \\
\hline $\begin{array}{l}\text { PWM/DC Motor } \\
\text { Control }\end{array}$ & $\begin{array}{l}\text { The Pulse Width Modulation (PWM) driven driver } \\
\text { of the caterpillar DC motor. }\end{array}$ \\
\hline $\begin{array}{l}\mu \mathrm{P} \text { Controller of } \\
\text { body orientation }\end{array}$ & $\begin{array}{l}\text { The microprocessor based controller board of body } \\
\text { orientation above the ground }\end{array}$ \\
\hline $\begin{array}{l}\text { Distance Sensors } \\
\text { (Body - Ground) }\end{array}$ & $\begin{array}{l}\text { Four distance sensors located on the four corners of } \\
\text { robot's body, providing analog distance information } \\
\text { for the body positioning. }\end{array}$ \\
\hline $\begin{array}{l}\text { Stepper Motors } \\
\text { (Legs Length) }\end{array}$ & $\begin{array}{l}\text { Four stepper motors, and their drivers, to control the } \\
\text { length of each leg of the robot. }\end{array}$ \\
\hline
\end{tabular}

The ability of a high-speed connection with an outside computer system is crucial for the easy implementation of the system on field.

In Table $1 \mathrm{a}$ brief description for the operation of each module shown in Figure 4 is provided to allow for a better comprehension of the system.

\section{TABLE 2: Software Description}

\begin{tabular}{|l|l|}
\hline \multicolumn{1}{|c|}{ Script name } & \multicolumn{1}{c|}{ Description } \\
\hline $\begin{array}{l}\text { Frame grabbing } \\
\text { and filtering }\end{array}$ & $\begin{array}{l}\text { The lowest software level of computer vision. Image } \\
\text { of the soil is dragged and accordingly with the } \\
\text { environmental conditions filtering of the image is } \\
\text { done. }\end{array}$ \\
\hline $\begin{array}{l}\text { Fast color } \\
\text { detection algorithm }\end{array}$ & $\begin{array}{l}\text { A fast and simple algorithm to detect the existence of } \\
\text { asparagus in an image. Speed is crucial to allow high } \\
\text { fps rate. }\end{array}$ \\
\hline $\begin{array}{l}\text { Body position } \\
\text { calculation }\end{array}$ & $\begin{array}{l}\text { Script for the initial position calculation of the robot } \\
\text { above an asparagus for further fine-tuned } \\
\text { positioning. }\end{array}$ \\
\hline $\begin{array}{l}\text { Asparagus tip } \\
\text { detection }\end{array}$ & $\begin{array}{l}\text { An image module to detect the asparagus module } \\
\text { accurately for precise head positioning. }\end{array}$ \\
\hline $\begin{array}{l}\text { Head accurate } \\
\text { positioning }\end{array}$ & $\begin{array}{l}\text { The calculation of the accurate head position above } \\
\text { asparagus tip. }\end{array}$ \\
\hline Robot movement & $\begin{array}{l}\text { The general movement script to control robot } \\
\text { movement in the field. The main operation module. }\end{array}$ \\
\hline $\begin{array}{l}\text { Robot position } \\
\text { monitoring }\end{array}$ & $\begin{array}{l}\text { Gathering information by the PID controller about } \\
\text { the current positioning of the body. May, interfere } \\
\text { with the operation of the microprocessor to achieve } \\
\text { better results. }\end{array}$ \\
\hline $\begin{array}{l}\text { Asparagus } \\
\text { positioning }\end{array}$ & $\begin{array}{l}\text { Script to control stepper motor, positioning the } \\
\text { cutting frame above the tip of asparagus. }\end{array}$ \\
\hline the asparagus. \\
collection
\end{tabular}

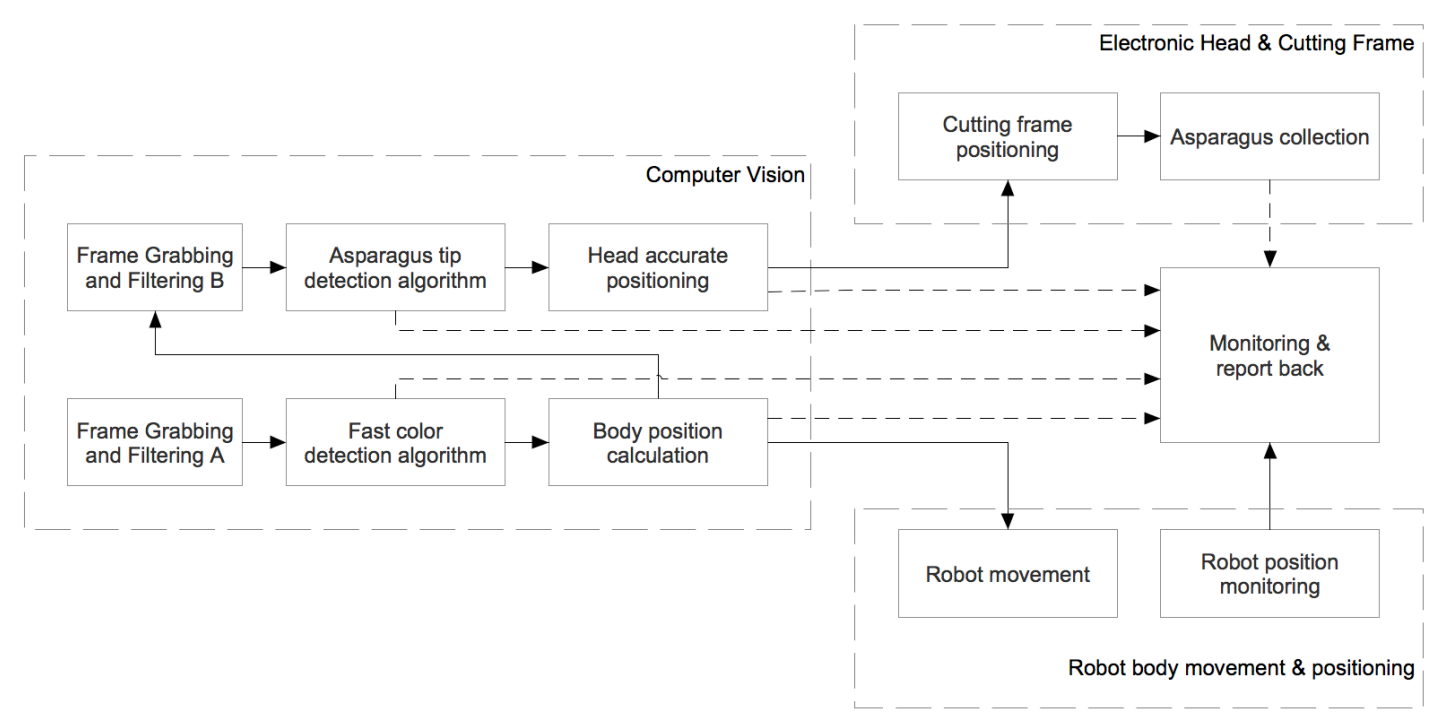

Figure 6: Software architecture / Flow chart 


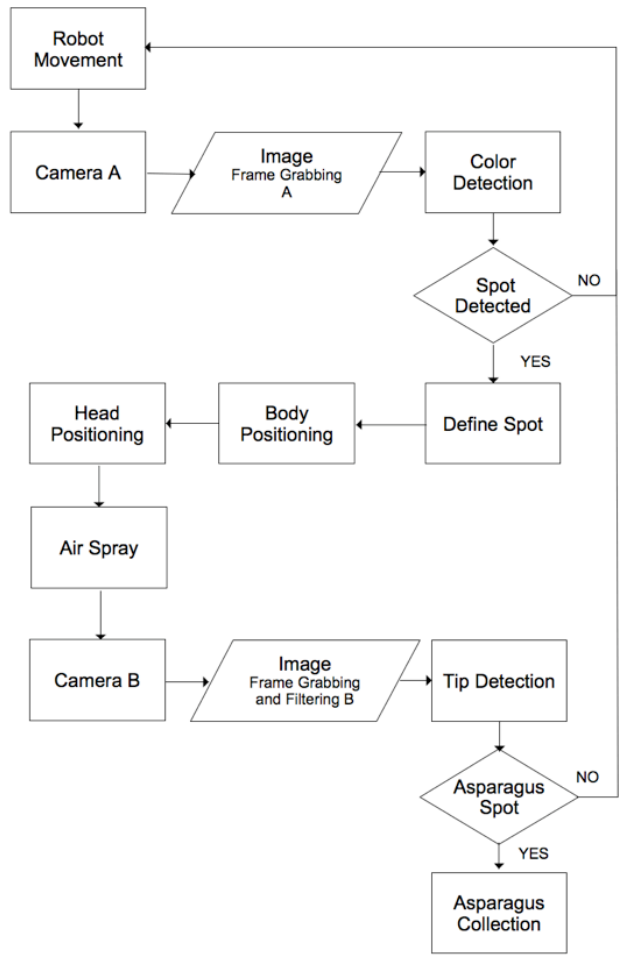

Figure 7: Operational flow chart

\section{Software and Control}

Control of the subsystems of the robot will be performed mainly by software. The Linux embedded system will control the various electronic modules using scripts implemented in $\mathrm{C}$. The architecture of the main program for the collector can be seen in Figure 6. In Table 2 the description and the purpose of each module is analyze

\section{Operation}

In Figure 7, the operation of the whole system is described via a flow chart.

In contrast with the proposed approach in [6], we propose a radically different method regarding detection of asparagus. The vision system of the robot incorporates two cameras (one in the robotic body and the other in the cutting frame) for the identification of asparagus tips. Once a vegetable is located by camera $\mathrm{A}$, the spot is detected and the robot approaches and gets prepared for the collection. The collection head takes position and utilizes the air spray to clear dust, Camera B grabs a frame and the tip of the asparagus is accurately identified and the collected by the gripper.

Extensive simulation experiments demonstrate particularly positive results. (We are currently conducting field experiments to calibrate the vision system and to assess its robustness in uncertain and variable soil and plant conditions.) Figure 8 illustrates an example of asparagus detection and identification. Asparagus spears are spotted utilizing a color detection algorithm. Other alternative methods that can be utilized are feature or edge detection and background subtraction.

\section{CONCLUSIONS}

Robot-environment interaction and robust sensing are critical aspects in the application of robotics in an outdoor and uncertain background. Novel mechatronic designs are essential for effective agricultural applications [7], [8]. In this context we presented a comprehensive design of a prototype robot for white asparagus harvesting. We argued that mechanical and autonomous harvest is feasible for the specific task and presented the architecture of a complete system by illustrating its mechanical, electronic, software and control aspects. Further work is focusing on field experiments and enhancements of the proposed concept.

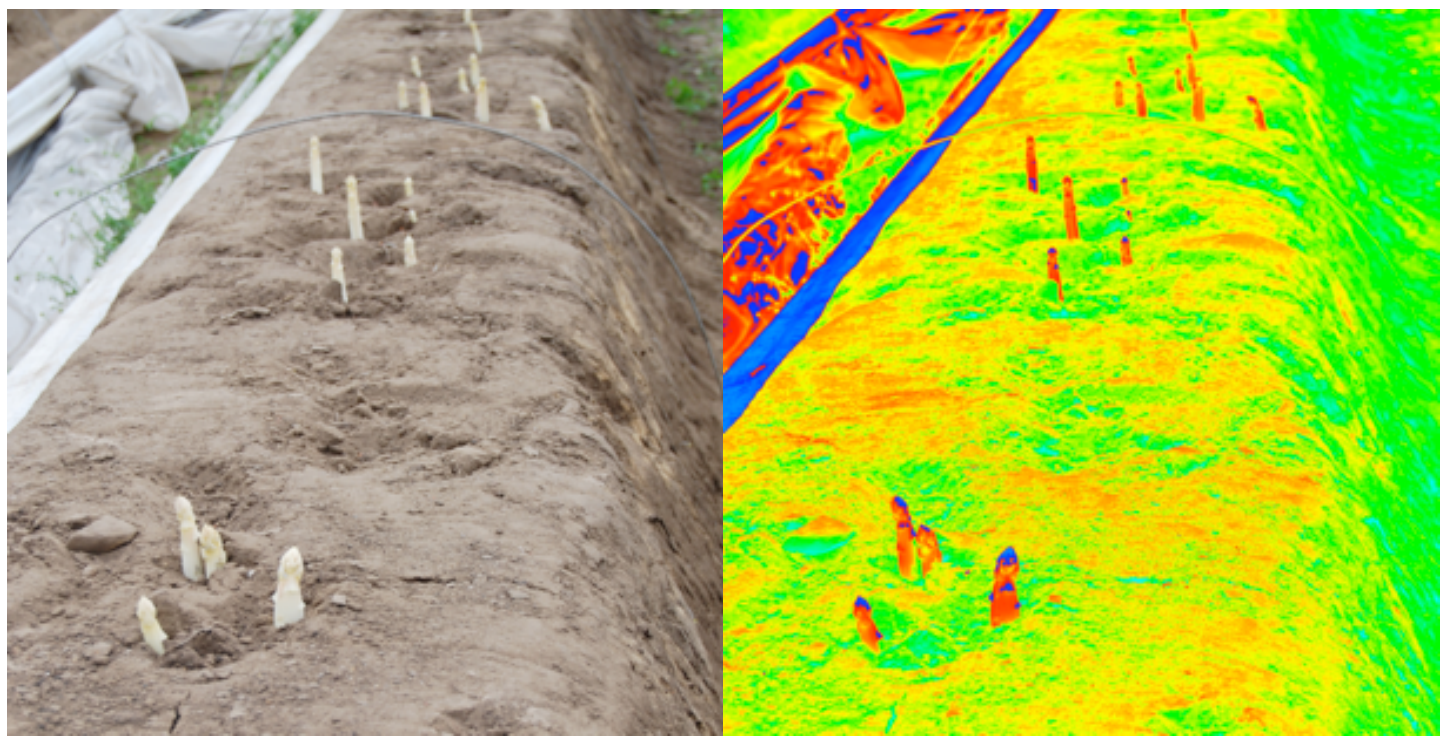

Figure 8: Filtered and Unfiltered Image 


\section{ACKNOWLEDGMENT}

The protype design presented in this paper achieved $19^{\text {th }}$ place out of a field of over 350 entries in the "Technogenesis" competition, an EU-funded project of the Region of Eastern Macedonia - Thrace in Greece to encourage business innovation.

\section{REFERENCES}

[1] D. E. Marshall, "Asparagus Mechanical Harvesting" December 1994 as ASAE Paper No. 94-1577, Annual meeting of the American society of Agricultural Engineers. Revised Sept. 6, 1996 and May 14, 2001.

[2] P.Y. Chua, T. Ilschner and D. G. Caldwell, "Robotic Manipulation of Food Products - A Review”Industrial Robot: An International Journal, vol. 30, No 4, pp. 345-354, 2003.

[3] M. Geyer, M. Jakob and S. Tischer. "Partly Mechanised Harvest of White Asparagus,"Information and Technology for Sustainable Fruit and Vegetable Production, FRUTIC 05, 12 - 16 September 2005, Montpellier France.

[4] G. Arndt, R. Rudziejewski, V. A. Stewart, "On the future of automated selective asparagus harvesting technology," Computers and Electrons:; in Agriculture, vol. 16 pp. 137-145 , 1997.

[5] G. Mattiazzo, S. Mauro, T. Raparelli and M. Velardocchia, "A Fuzzy Controlled Pneumatic Gripper for Asparagus Harvesting," Control Engineering Practice, vol. 3, no. 11, pp.1563-1570, 1995.

[6] P. Baylou, B. El Hadj Amor, M. Monsion, C. Bouvet and G. Bousseau, "Detection and Three-Dimensional Localization by Stereoscopic Visual Sensor and its Application to a Robot Picking Asparagus," Pattern Recognition, vol.17, no.4, pp.337-384, 1984.

[7] R. Ceres, J. L. Pons, A.R . Jiménez, J. M. Martin and L. Calderon, "Design and implementation of an aided fruit-harvesting robot (Agribot)," Industrial Robot, vol. 25, No. 5, pp. 337-346, 1998.

[8] J. N. Reed, S. J. Miles, J. Butler, M. Baldwin and R. Noble, "Automatic Mushroom Harvester Development," Journal of Agricultural Engineering Research, vol.78(1), pp.15-23, 2001 